\title{
FB720 project: development of new solar control glazing with passive seasonal discrimination of solar radiation incomes
}

\author{
Pablo Garrido $^{1} \cdot$ Joan Lluís Zamora $^{2} \cdot$ José Manuel Marco $^{3} \cdot$ Moisés Lostao $^{3}$
}

Received: 8 October 2014/ Accepted: 29 April 2015/Published online: 30 May 2015

(c) The Author(s) 2015. This article is published with open access at Springerlink.com

\begin{abstract}
Currently, the most balanced technical solution for sun protection of glazed areas is the Venetian blind, because it prevents the entry of direct solar radiation, but at the same time provides a view of the outside and allows light to diffuse into the building. The current challenge is to find an improved, integrated technical solution at an affordable cost that requires low maintenance, is suitable for every geographical situation (latitude) and adaptable to each orientation of building façades. The solar control glass façade FB720 presented here integrates into a single structural element the advantages of protective glass and Venetian blinds.
\end{abstract}

Keywords Solar control glazing - Lightweight façade · Passive seasonal discrimination · Solar protection index value

Joan Lluís Zamora

joan.1luis.zamora@upc.edu

Pablo Garrido

pablogarrido@b720.com

José Manuel Marco

duglass@duglass.com

1 b720 Arquitectos, Josep Tarradellas 123, 08021 Barcelona, Spain

2 Laboratori d'innovació i Tecnologia a l'Arquitectura (LiTA), Universitat Politècnica de Catalunya (UPC), Barcelona, Spain

3 Ariño Duglass, La Puebla de Alfindén, 50171 Zaragoza, Spain

\section{Introduction}

Modern office buildings often have large glazed areas. Depending on the climate zone, incident solar radiation on fenestration can lead to high cooling demands during hot periods, although solar radiation can help reduce heating demands during cool periods. Previous studies have shown that a large proportion of the net energy demand of an office building is related to window heat loss and cooling demands induced by solar irradiance. Some experts [1] found that, even in what traditionally has been considered to be a heating-dominated climate, cooling demands dominate the net energy demand of an office building. Solar shading systems are vital to reduce the cooling demand of an office building and might also be necessary to reduce glare issues. In the tropics, glazed façade is also the cause of large solar heat gains inside buildings, and researchers [2] are focusing on reducing solar heat (infrared) transmittance and daylight (visible light) transmittance. It was also observed [3] that, in the case of double glazing units (DGU), the use of a solar control film is highly recommended to increase the separation between the sheet glasses. The energy gain was reduced by $55 \%$ compared to the traditional DGU without solar control film. Fixed shading devices (e.g. vertical fins, diagonal fins and egg crate) are used to protect inner spaces from direct solar gain through openings, windows and large glazed surfaces to control air temperature and improve the illuminance level. The results [4] showed that the temperature in offices with shading devices was reduced to an acceptable level compared to offices without shading devices. The visual environment was improved by controlling the illuminance level, improving uniformity and eliminating glare. Other researchers [5] recommend accurately estimating the optical properties of the different types of dynamic shading 
devices (such as roller blinds and Venetian blinds) and including their effects in the glazing system analysis. The Venetian blind is an interesting solution because it blocks direct solar radiation, whilst enabling the transmission of diffuse radiation indoors. Further progress is inextricable linked to the dynamic control of sunlight and optimal control of solar heat gains, taking into account the variability in the solar radiation spectra incident on the building's envelope and the variability in outdoor and indoor air temperature differences. Tuning control [6] of glazing's transmittance dependence on the solar radiation wavelength is required to optimise daylighting with reference to people's needs (their health and comfort) and energy (thermal and electrical load minimization). However, the energy-saving potential of regulating solar spectrum response properties is greater than that of regulating the longwave thermal emission property in summer; the trend is reversed in winter [7]. By properly regulating the NIR spectrum transmission and reflection properties and the long-wave thermal emission property, the performance of ordinary glazing can be improved to approach the perfect window for summer or winter. An advanced fenestration system must combine the functions of daylighting regulation, glare protection and seasonal thermal control.

Currently, float glass products for façade glazing are available with a variable solar protection index value, obtained by the interposition of different kinds of solar radiation filters (microlouvers, metal mesh, etc.) or by alternating with reflective microprism surface treatments. However, these conventional protection solutions have three main disadvantages: they do not take into account the varying conditions of solar incidence due to latitude or the different orientations of each façade, and it is difficult to incorporate free glazing areas without any protective solar treatment in the same unit of glass. There is a search for innovative coatings to redirect incident solar radiation, thus simultaneously reducing glare and projecting daylight deep into the room. The solar gains are reduced for chosen angles corresponding to aestival elevations of the sun, thereby minimising heating loads in winter and cooling loads in summer. Ray-tracing programs [8] have been developed to optimise structures with the aforementioned goals. The chosen solution is based on embedded reflective surfaces that can be combined with a standard double glazed window.

The current challenge is to find a technical solution that is:

- Affordable

- Low maintenance

- Suitable for every geographical situation

- Adaptable to each of a building's façades

The aim of the research project FB720 (IDI-20090761) was to design and develop a lightweight façade for office buildings with low environmental impact and high energy efficiency, mainly for use in temperate climates, as in Spain [9]. One of the technical strategies to achieve this is the integration of new glass with passive seasonal discrimination of solar radiation incomes. The ultimate purpose of this strategy is to obtain clearly differentiated solar protection index values throughout the year, according to the angle of incidence of solar radiation. This strategy facilitates the desired thermal gains in the winter and reduces unwanted thermal contributions in the summer, without a loss of external views.

\section{Methods}

Unlike other solar control fenestration, FB720 solar control glass is based on the possibilities offered by the superimposition of various layers of glass in the case of laminated glazing. Solar control is achieved by means of a reflective coating treatment applied on every layer of glass [10] with a singular geometric pattern that is tailored to the specific characteristics of each architectural project; mainly the building façade's orientation and the latitude position of the building (Fig. 1). The geometric pattern applied to each of the glass layers is slightly shifted on every layer to achieve a volumetric filtering effect similar to Venetian blinds, but without the inconvenience of handling and maintaining these types of blinds. The result is a customized laminated glass containing what could be described as "virtual slats", which are designed to provide the highest protection from the incidence of direct solar radiation in summer and the greatest collection of solar energy in winter.

The procedure for designing the ideal geometric pattern of the "virtual slats" is based on different strips of metallic reflective coatings applied to both sides of the glass. The alignment and superimposition of these strips are designed in relation to the maximum angles of incidence of radiation during the winter and summer solstices in the façade plane, corrected by the refraction index of the glass material (Fig. 2). The exact pattern for every situation is deduced using trigonometry calculations, the details of which are outside of the scope of this paper. The end objective is to achieve the same passive protection effect as that produced by an eave over a façade oriented towards the midday sun: in the northern hemisphere it provides protection from radiation in the summer, but enables much of the radiation to enter the building in the winter. The key is the geometric arrangement of the strips compared to the angle of incidence of the sun during the winter and summer solstices, or in other words, the angle of incidence at the equinox plus the angle of declination in the summer $\left(+23.4^{\circ}\right)$ or minus the angle of declination in the winter $\left(-23.4^{\circ}\right)$. To achieve 

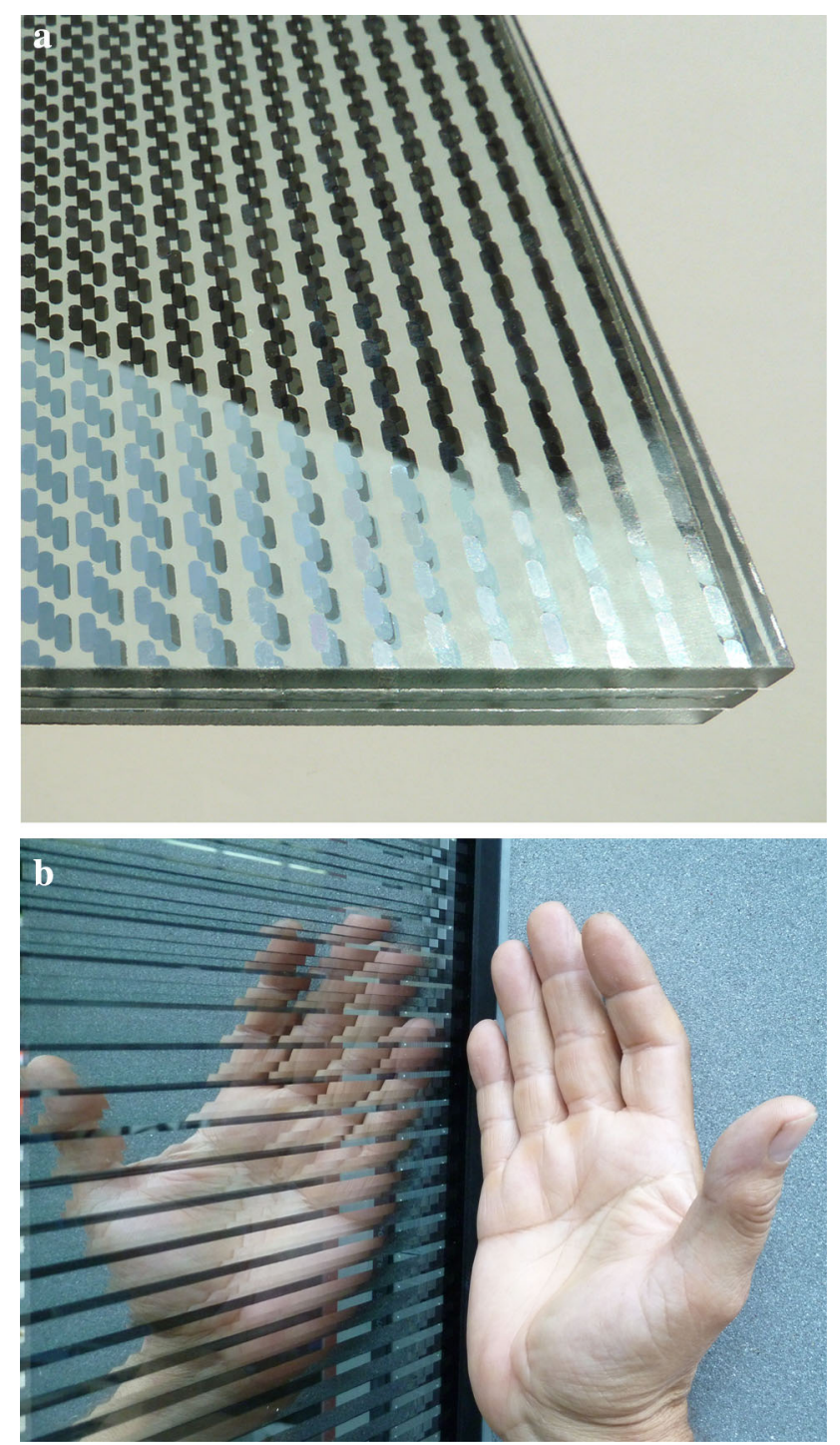

Fig. 1 Upper sample a with 3 overlayed reflective coatings in a "pill pattern". Lower sample b with 3 overlayed reflective coatings in a "strip pattern"
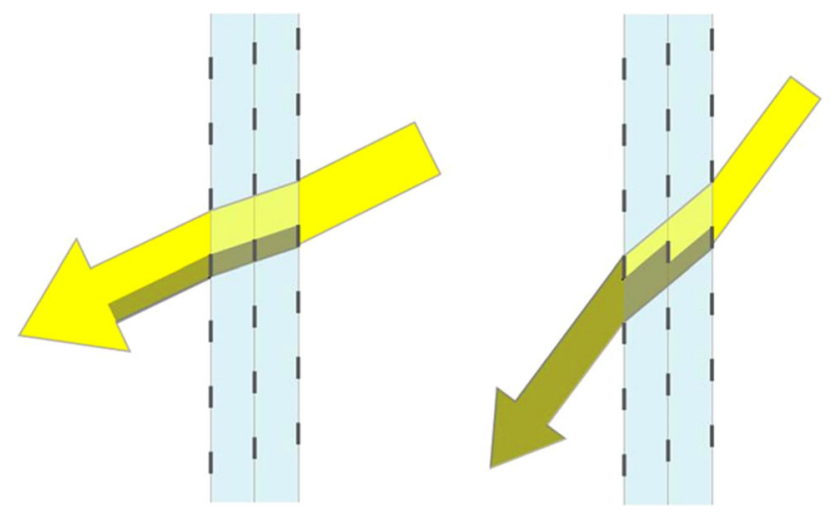

Fig. 2 Concept effect of solar radiation reflective strips on solar radiation control. Left incidence angle of solar radiation in the winter. Right incidence angle of solar radiation in the summer this effect at any orientation, the arrangement of the strips on the plane of glass is determined by the geometric intersection between the façade and the plane of the sun's path at the equinox. It will vary depending on the orientation of the glass and the latitude of the site. Thus, the best pattern for a southern orientation (in the northern hemisphere) will be comprised of horizontal strips, whilst in an eastern or western orientation the strips should slope with an angle of inclination equal to the co-latitude (Fig. 3). The offset between the strips in the different layers is determined by the angles of declination in summer and winter, with respect to a geometric reference plane perpendicular to the façade and to the alignment of the protective strips.

The width of the strips, the distance between them and the offset in alignment are determined by the number and thickness of glass layers in the glazing unit. As more superimposed layers are used, the strips can be separated by a greater distance (Fig. 4). In the practical cases that were studied, a minimum of three layers created by a reflective and semi-transparent coating of metal oxides on the surface of the glass was considered [11].

\section{Glass coating design}

The technique developed for the selective metallization of glass makes possible the application of complex multilayer structures, either as strips, strips or as separate spots with varying degrees of transparency, reflection and metallic colour (copper, gold, bronze, etc.).

Energy-control coatings for architectural purposes form a specific area within the general field of thin-layer interference filters. The most common industrial technique for manufacturing interference filters on large sheets of glass is magnetron sputtering (MS). This technique has several major advantages: different materials can be used; complex, multilayer structures can be deposited; and it can be scaled-up to industrial facilities. The following points were taken into account in particular in the design of the coating:

1. Photo-energy properties.

2. Aesthetics.

3. Durability.

4. Materials and production.

The first two points are related to the spectral behaviour of the coating and, therefore, can be considered fundamental aspects of the optical design of the multilayer structure. Points 3 and 4 are related to materials and their processing properties and should be taken into account in the design as they limit the range of materials that can be used.

In an assessment of the final properties of a specific design, three main photo-energy factors should be considered: the solar factor (SF), which describes the energy gain due to the incidence of solar radiation; the $U$ value or heat transfer 


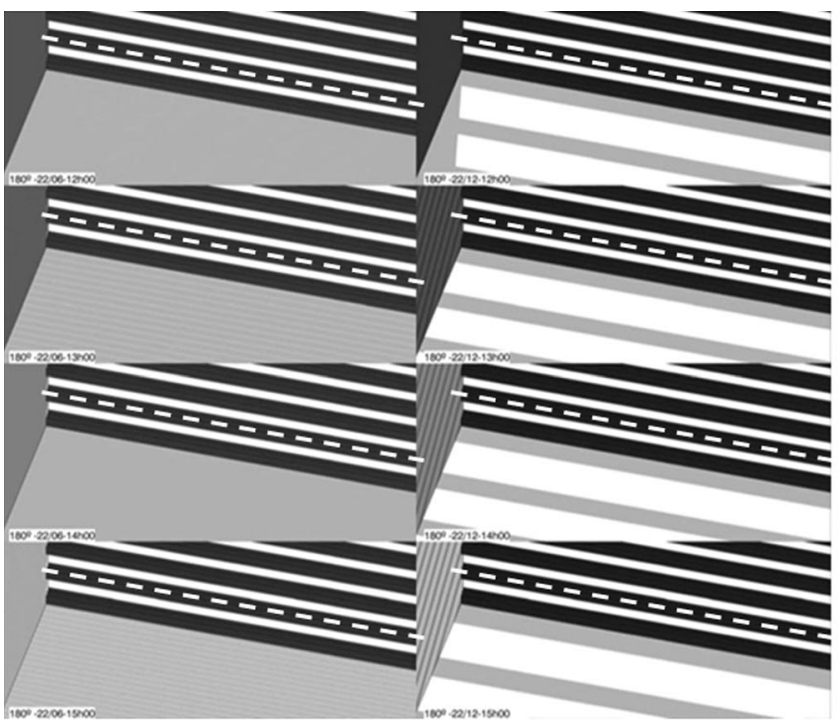

Fig. 3 3D view showing the evolution of the shadow generated on a horizontal plane by the contribution of solar radiation reflective strips (12 PM; 1 PM, 2 PM; 3 PM). The white dotted lines show the slope of the strips in each orientation. From left to right south pattern, summer

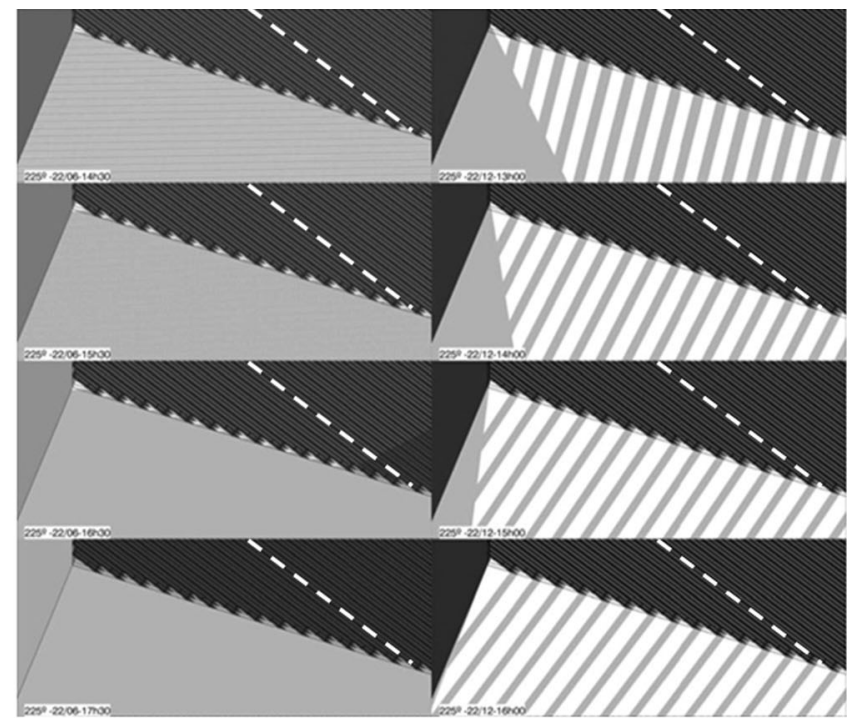

solstice; south pattern, winter solstice; west pattern, summer solstice; west pattern, winter solstice. During the summer solstice, the obstruction is total throughout the day, whilst during the winter solstice the obstruction is minimum, to allow solar radiation to enter the building
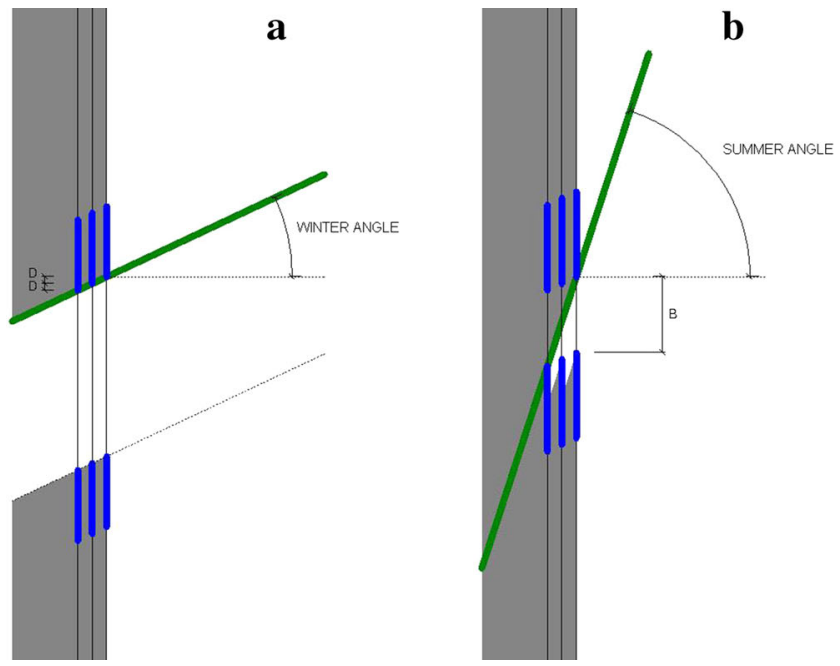

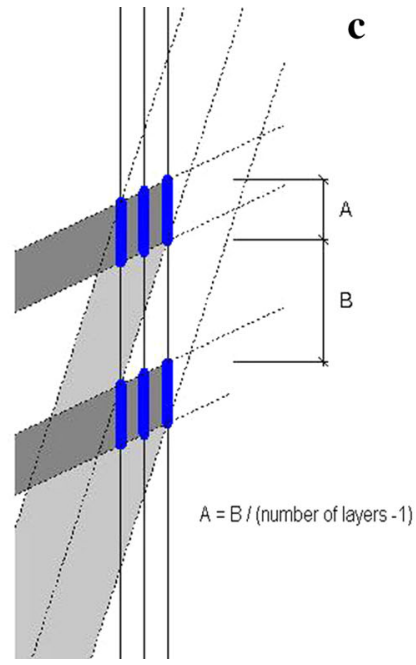

Fig. 4 Geometric deduction of the dimensions and basic arrangement of the reflective strips. The plane of the paper in this article corresponds to a virtual vertical plane arranged perpendicularly to the plane of the façade. In a, starting from the maximum angle of the sun's path in winter (the angle of incidence at the equinox minus the angle of declination in winter), the reflective strips are aligned in a series of steps. In b, starting from the maximum angle of the sun's

coefficient, which indicates the heat loss or gain due to differences in temperature between the interior and exterior of the building; and the light transmission (LT), which is important to predict the degree of interior illumination and the artificial lighting requirements.

The determination of the optimal properties of the solar control glass depends, to a great extent, on the geographic situation of the building and on other aspects related to the path in summer (the angle of incidence at the equinox plus the angle of declination in the summer), the separation $(B)$ of the reflective strips' planes is established. In $\mathbf{c}$ the width $(A)$ of the strips in one plane depends on the number of superimposed layers, 3 in this example. For the real, more precise calculation the angle of diffraction of the ray of light as it crosses the glass should also be taken into account

building design: the orientation, the glazed areas, the inclination of the façades or skylights and the existence of other solar control measures, among other factors.

In this case, a very reflective coating was developed with transmission values of less than $5 \%$. The colour of the coating was completely neutral in reflection and transmission. Its optical properties were determined with spectrophotometry VIS-NIR (Fig. 5). 


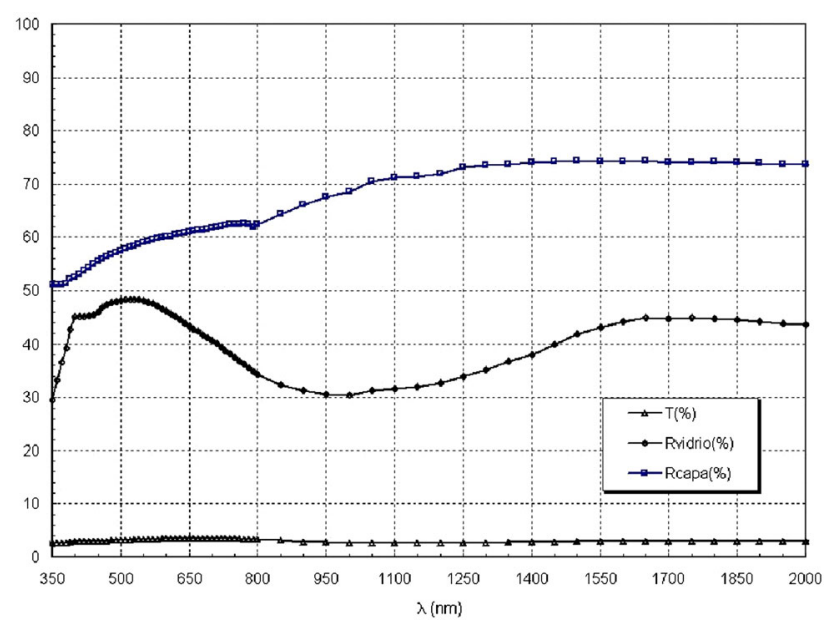

Fig. 5 Optical properties of the glazing coating used in the samples. $\mathrm{Tl}$ light transmission, Rvidrio glass reflection, Rcapa coating reflection

Table 1 Structure of the multilayer that was developed

\begin{tabular}{ll}
\hline Air & Thickness (nm) \\
\hline $\mathrm{TiN}_{\mathrm{X}}$ & 5 \\
$\mathrm{NiCr}$ & 38 \\
$\mathrm{SnO}_{\mathrm{X}}$ & 10 \\
\hline Glass & \\
\hline
\end{tabular}

Table 2 Overall optical properties of the multilayered glass

\begin{tabular}{lc}
\hline Global factors & \\
\hline Coating on 6 mm clear glass & \\
Light transmission & $3.20 \%$ \\
Light reflection glass side & $6.00 \%$ \\
Light reflection coat side & \\
Colour coordinates & \\
$\mathrm{L}^{*}$ & 74.3 \\
$\mathrm{a}^{*}$ & -2.8 \\
$\mathrm{~b}^{*}$ & 1.1 \\
Solar transmission & $3.8 \%$ \\
Solar reflection & $24.8 \%$ \\
\hline
\end{tabular}

To obtain all of these properties, we opted for a structure based on a metallic layer combined with dielectric interference layers. Using this structure, the reflected colour can be varied by the anti-reflection of certain wavelengths, which is caused by the dielectric layer. By increasing or decreasing the thickness of this layer, the wavelength at which anti-reflection occurs can be altered, which in turn changes the colour that is reflected. In the first design, a structure was designed that has a neutral tone, is very reflective and has low radiation transmission. This provides

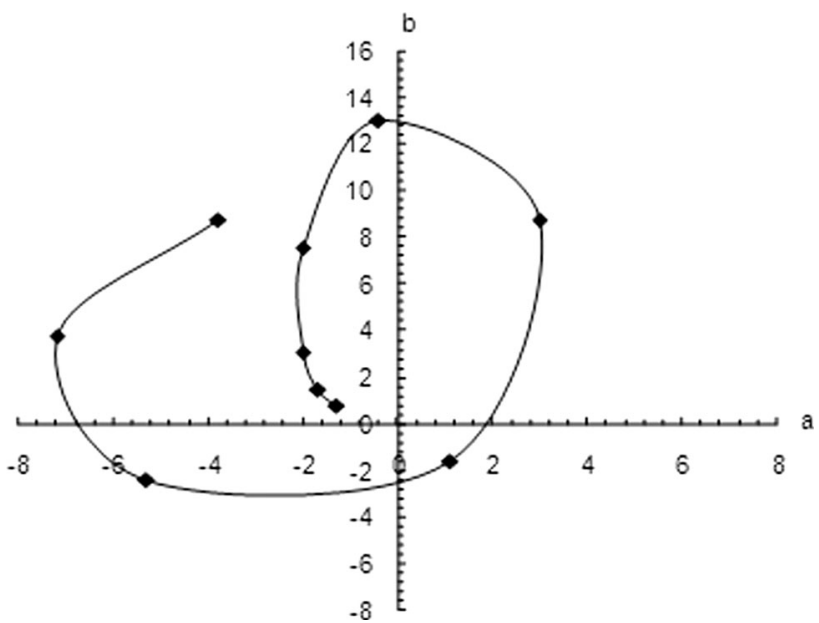

Fig. 6 Colour coordinates in the CIE Lab 1976 system provided by a structure of the following type: Glass/dielectric/metal/dielectric by varying the thickness of the dielectric layers from 0 to $100 \mathrm{~nm}$. The colour channels, $a^{*}$ and $b^{*}$, will represent true neutral gray values at $\mathrm{a}^{*}=0$ and $\mathrm{b}^{*}=0$. The red/green opponent colours are represented along the $\mathrm{a}^{*}$ axis, with green at negative $\mathrm{a}^{*}$ values and red at positive $a^{*}$ values. The yellow/blue opponent colours are represented along the $b^{*}$ axis, with blue at negative $b^{*}$ values and yellow at positive $b^{*}$ values. The scaling and limits of the $a^{*}$ and $b^{*}$ axes will depend on the specific implementation of Lab colour, but they often run in the range of \pm 100 or -128 to +127

better solar protection for the selective glazing, with angle discrimination (Tables 1,2).

Optical interference can be used to obtain a wide range of colours by varying the characteristics of the coatings. For example, if a dielectric-metal-dielectric structure is used and the thickness of the dielectric layers is varied, we can obtain a whole range of colours. This is shown in the chromatic diagram (Fig. 6) in which the thickness of the dielectric layers varied between 0 and $100 \mathrm{~nm}$. Thus, the aesthetic properties of the glass can be adapted for use in different architectural designs.

\section{Design for seasonal discrimination}

The main aim of passive seasonal discrimination is to align shade from "virtual blinds" in winter and superimpose it in summer. This provides passive solar control that is both variable and seasonal. In other words, the solar factor is lower in the hot months and higher in the cold ones (Fig. 7a, b). On the basis of these criteria, various samples and models were developed. One of the main technical limitations to consider is tolerance in the relative position of the various strips: for correct functioning, precision must be less than $0.1 \mathrm{~mm}$.

The overall visual transmission characteristics of the FB720 solar control glazing are highly dependent on the transparency and reflectivity of the different materials in the strips. Although the glass usually provides good 


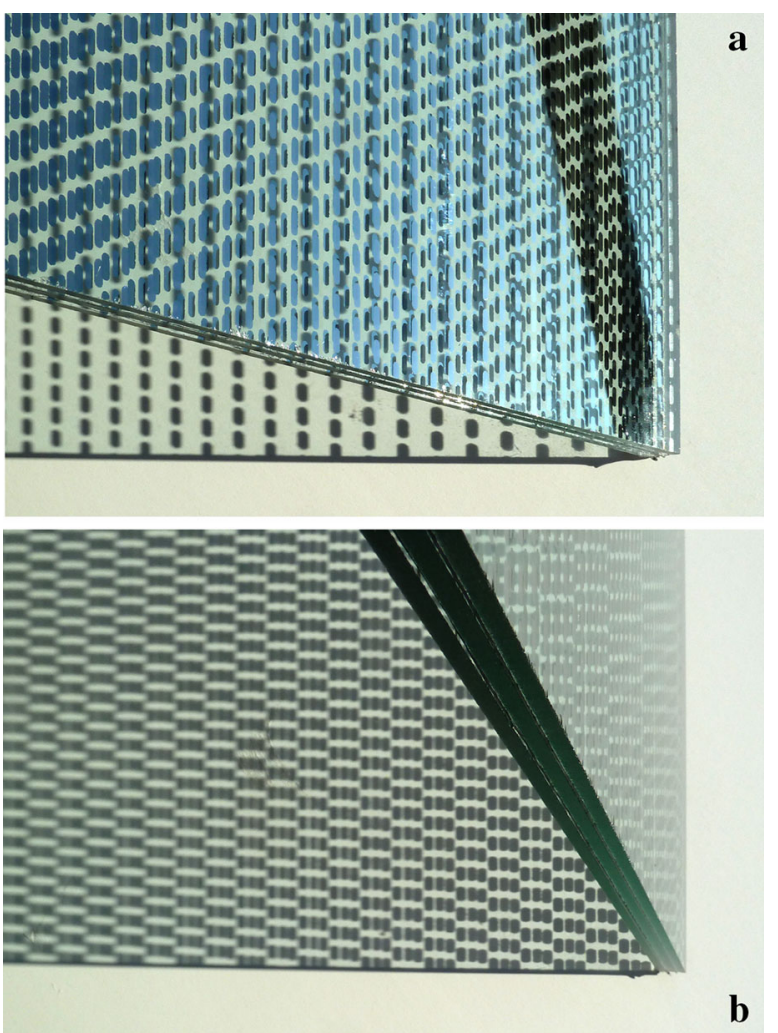

Fig. 7 a, b Visual recreation of how the variable angle of incidence of direct solar radiation affects the shade. The upper image (Fig. 7a) would correspond to the angle of incidence of the sun at the summer solstice so that the shadow of the strips on a horizontal plane (the floor) is aligned. The lower image (Fig. 7b) corresponds to the angle of incidence of radiation at the winter solstice so that the shadow of the strips on a horizontal plane (the floor) is superimposed, which reduces the total energy transmitted to the interior of the building by direct solar radiation on the horizontal plane

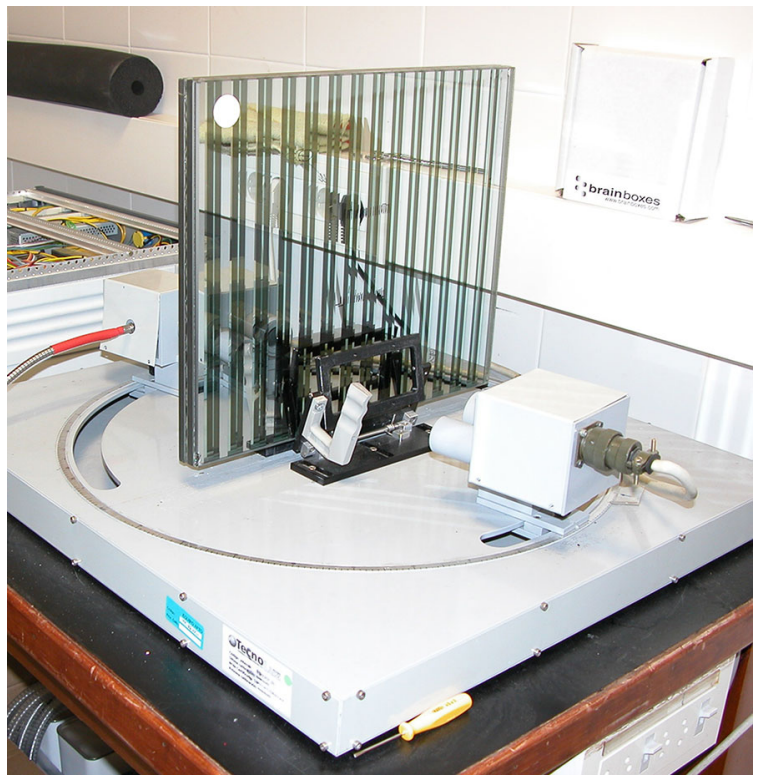

Fig. 8 UV-VIS-IR spectrometer to measure direct light reflection and transmission measured visibility, it is not totally transparent. Visibility through the glass depends on the contrast between the exterior and interior lighting. However, this variability produces some interesting aesthetic features because the attractive appearance changes throughout the day.

The standard calculation software could not be used in this case to determine the light and energy properties of the FB720 glazing, as the surface of the multilayered glass under study does not have uniform reflective characteristics. Therefore, a simulation tool was developed to calculate the light transmittance and reflectance values

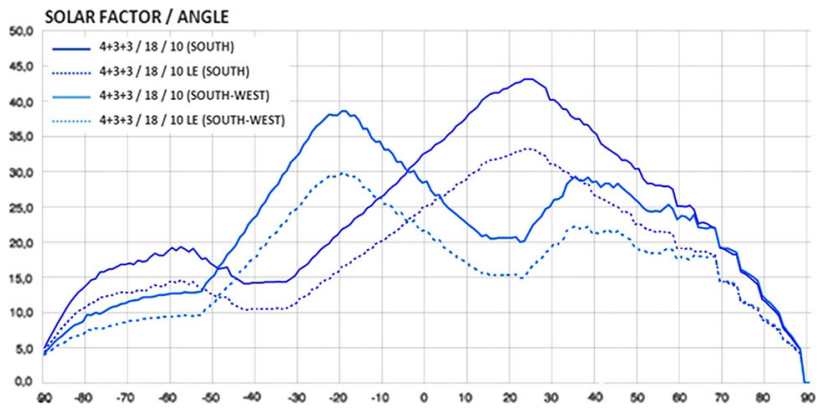

Fig. 9 Solar factor ( $y$, ordinate) values, depending on the solar radiation angle of incidence ( $x$, abscissa). The curves correspond to different glass compositions (laminated glass + chamber + monolithic glass) and geometric patterns designed for latitude $41^{\circ}$ (the orientation for which the corresponding geometric pattern is designed is given in brackets). The selective arrangement of the reflective strips enables the maximum and minimum levels of the solar factor to be adjusted, according to the angles of incidence at the summer and winter solstices. For example, for patterns designed for a southern orientation, the maximum solar factor value (situation of minimum protection) coincides approximately with the angle of incidence in winter of $25.6^{\circ}$; whilst for the summer angle of $72.4^{\circ}$, the solar factor value (situation of maximum protection) is approximately half. At greater angles of incidence, found at lower latitudes (close to the equator), the solar factor value drops even further proportionally, due to the increase in the reflection coefficient of the glass

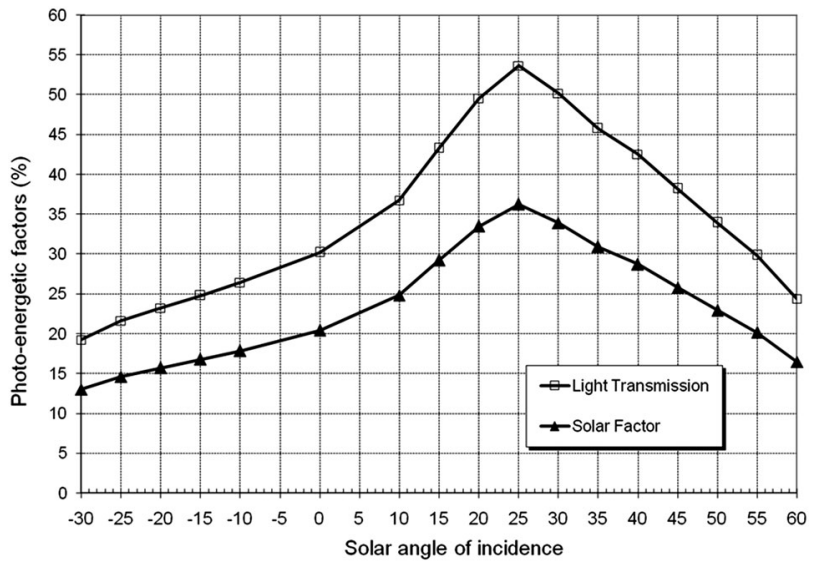

Fig. 10 Angular dependence of light transmission and the solar factor, measured by spectrophotometry 
Table 3 Measured photo-energy properties as a function of the angle of incidence

\begin{tabular}{lll}
\hline $\begin{array}{l}\text { Solar angle of } \\
\text { incidence }\end{array}$ & $\begin{array}{l}\text { Light transmision } \\
(\%)\end{array}$ & $\begin{array}{l}\text { Solar transmision } \\
(\%)\end{array}$ \\
\hline-30 & 19.2 & 13.0 \\
-25 & 21.6 & 14.6 \\
-20 & 23.2 & 15.7 \\
-15 & 24.8 & 16.8 \\
-10 & 26.4 & 17.8 \\
0 & 30.2 & 20.4 \\
10 & 36.7 & 24.8 \\
15 & 43.3 & 29.2 \\
20 & 49.5 & 33.5 \\
25 & 53.6 & 36.2 \\
30 & 50.2 & 33.9 \\
35 & 45.7 & 30.9 \\
40 & 42.5 & 28.7 \\
45 & 38.2 & 25.8 \\
50 & 33.9 & 22.9 \\
55 & 29.8 & 20.2 \\
60 & 24.4 & 16.5 \\
\hline
\end{tabular}

according to the angle of sun incidence, based on the "Intersystems Caché" tool: a database for high-performance objects. Due to the periodicity of the geometric patterns, calculations can be made for one period and extrapolated.

\section{Results and discussion}

The first results obtained with calculation tools confirmed the passive seasonal discrimination behaviour of the FB720 glazing. The solar factor value for the angle of incidence of solar radiation at the summer solstice is $50 \%$ of the solar factor value for the angle of incidence of solar radiation at the winter solstice for Barcelona's latitude (Fig. 9). These results were compared with experimental tests carried out in the laboratories of the University of Zaragoza's Department of Applied Physics. A UV-VIS-IR spectrometer was used to measure the values of the transmittance and reflectance factors simultaneously in the range of 200-2500 nm light frequency, which is typical of solar radiation. Measurements were made for different degrees of incidence of the light beam (Figs. 8, 9, 10; Table 3).

Using the values obtained, we could determine the variation in solar factor and light transmittance of the samples according to the angle of incidence. The results coincided with the estimations of theoretical behaviour with an acceptable level of accuracy. Therefore, the simulation tool was validated.

On the basis of these preliminary values, several additional simulations were carried out to evaluate the energy behaviour of the FB720 glazing. The theoretical energy demand for heating, cooling and lighting in a standard office module was compared for different façade systems using "Tas Building Designer" and "eQUEST" software. The simulation is not described in detail here, as
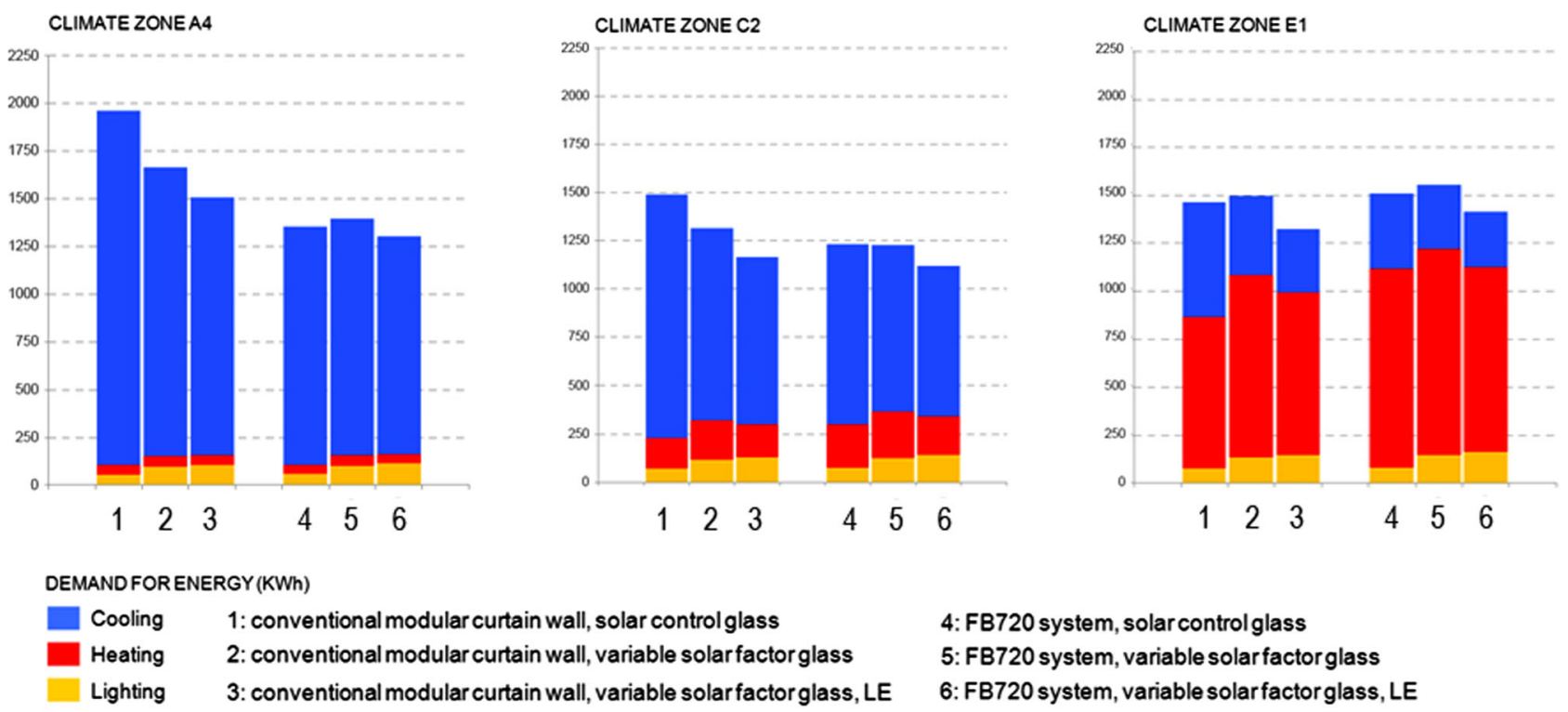

Fig. 11 Comparative study of the energy demand (y,ordinate, kWh) associated with different types of glazed façade oriented to the south in different climate zones in the Iberian Peninsula (A4: Almería; C2: Barcelona; E1: Burgos). Types 2, 3, 5 and 6 correspond to the use of
FB720 glass with different patterns of reflective strips; types 1 and 4 correspond to a conventional glazed façade, with quality solar control glass. In all cases, buildings have a high internal load and the glass covers $75 \%$ of the total surface of the façade 

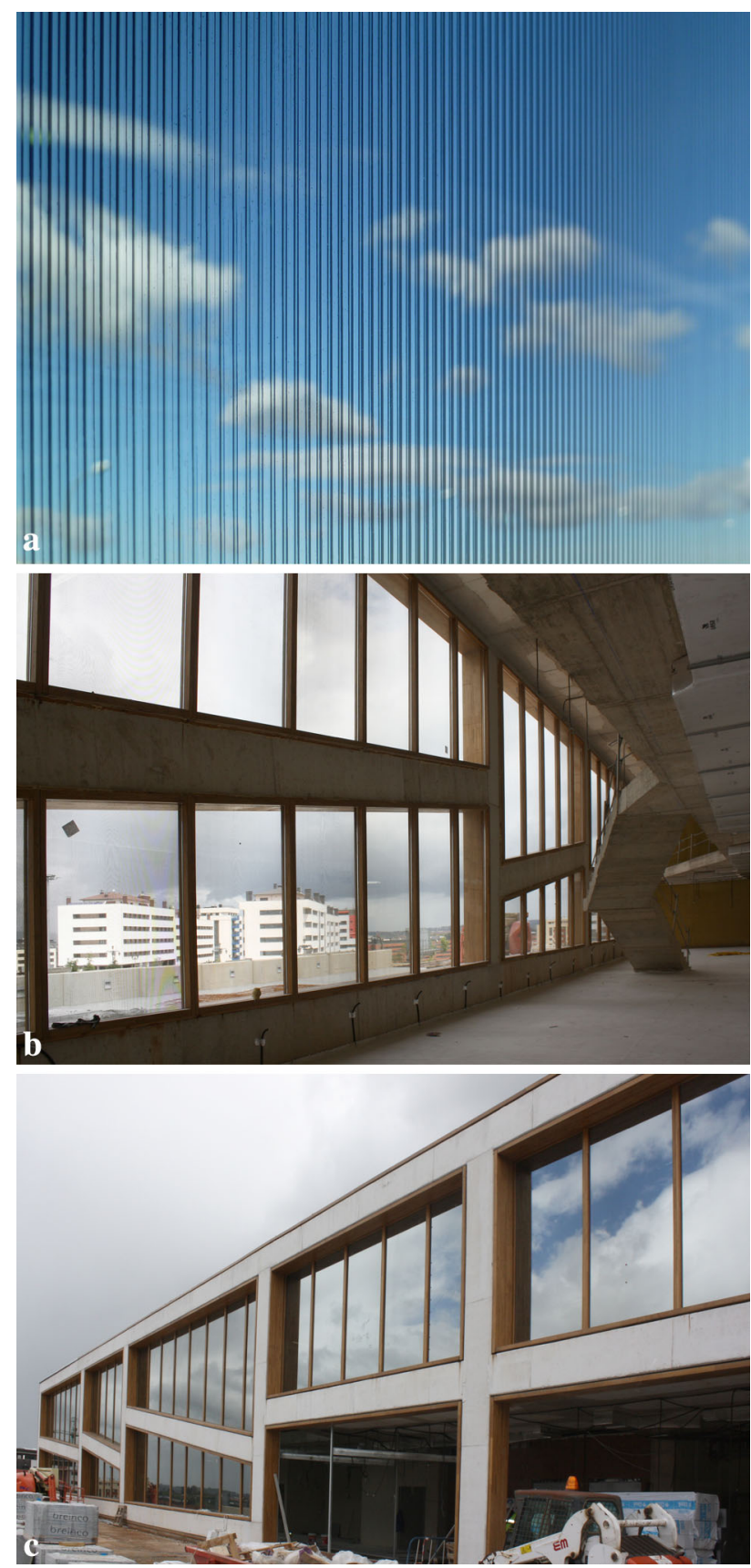

Fig. 12 Ibermutuamur Building (Oviedo) Spain. (Spring 2013). Design by B720 Arquitectos, PMMT and Vicente Benéitez Architects. Glazing by Ariño Duglass. upper (a) close-up view of the vertical strip pattern used in the NW façade. central (b) and lower (c) general views of the façade, from inside and outside. This is the first real façade in which the technology developed in the FB720 project has been applied. In this case, the main objective of the treatment was to protect from the glare of the sun from the west in the summer months. To achieve this, a simple pattern of three vertical, superimposed strips was used

it is outside the scope of the paper. However, preliminary results show that the use of FB720 glazing in a geographical situation such as the Iberian Peninsula may lead, in some cases, to a $30 \%$ lower energy demand than standard solar control glazing (Fig. 11). The glazing was most efficient in the most extreme summer climate conditions (high solar radiation, clear skies and a high average outside temperature) and when the use of the building involved a high internal thermal load, for example, when it was used for administrative or teaching purposes. In buildings with these uses, it may be particularly useful to have a façade that is passive, has low maintenance requirements, does not need to be handled by the user and users do not need to be trained to achieve the best results. FB720 glazing is also more efficient when the orientation of the façade is similar to the orientation of the sun at midday. For example, in the northern hemisphere the best use of the capacities of FB720 glazing is obtained in façades with southeast to southwest orientations. The viability of FB720 glazing for practical applications has been verified. At the time of writing this paper, the first real building with FB720 glazing in its façade had been completed (Fig. 12).

\section{Conclusions}

The FB720 glazing for protection of solar radiation has numerous qualitative and quantitative advantages over other conventional solar control glazing systems used in temperate climates (external blinds, external reflective layers, coloured glass, etc.):

- Customizes the solar protection to each geographical site, building, façade plan and even each glazing unit and does not depend on the actions of the user.

- Discriminates solar radiation incomes passively: thermal incomes are welcome only in winter periods.

- Incorporates in the same pane of glazing various degrees of transparency and visibility. Solar protection can be achieved using a wide range of coatings on glass, with varying levels of reflection, transparency and colour.

- Fosters more reliable building envelope results: it can even be combined with decorative coatings. Passive solar protection leads to more reliable building envelope results.

- Reduces construction and maintenance costs.

FB720 glazing can be combined with other glazing technologies (double glazing, low emissivity, airborne sound, etc.) to achieve more complex envelope systems.

Authors' contributions Pablo Garrido is a member of b720 Arquitectos, the architect's studio behind this research project. Joan Lluís Zamora is the coordinator of the UPC research team that supports the research project. José Manuel Marco and Moises Lostao work at the industrial 
corporation Ariño, which was responsible for manufacturing and developing the industrial prototypes.

Acknowledgments The Façade FB720 project is the result of research funded by the Spanish Government's Centre for Industrial Technological Development (Centro para el Desarrollo Tecnológico Industrial, CDTI) (IDI-20090761).

\section{Conflict of interest None.}

Open Access This article is distributed under the terms of the Creative Commons Attribution 4.0 International License (http:// creativecommons.org/licenses/by/4.0/), which permits unrestricted use, distribution, and reproduction in any medium, provided you give appropriate credit to the original author(s) and the source, provide a link to the Creative Commons license, and indicate if changes were made.

\section{Appendix: List of abbreviations used (if any)}

- The FB720 project is the result of research funded by the Spanish Government's Centre for Industrial Technological Development (Centro para el Desarrollo Tecnológico Industrial, CDTI) (IDI-20090761).

- The VIS-NIR spectrometer can be used to obtain total reflection specifications over the complete solar spectral range. As half of the solar radiation energy is situated in the NIR range, it is important for many applications to cover the complete emission range of the sun (on earth) from 360 to $2500 \mathrm{~nm}$.

- UV-VIS-IR spectrometer refers to absorption spectroscopy or reflectance spectroscopy in the ultravioletvisible and infrared spectral region.

- InterSystems Caché ${ }^{\circledR}$ is an advanced database management system and rapid application development environment.
- eQUEST simulation software can be used to calibrate energy consumption.

\section{References}

1. Grynning, S., Time, B., Matusiak, B.: Solar shading control strategies in cold climates - Heating, cooling demand and daylight availability in office spaces. Sol. Energy 107, 182-194 (2014)

2. Qahtan, A., Rao, S.P., Keumala, N.: The effectiveness of the sustainable flowing water film in improving the solar-optical properties of glazing in the tropics. Energy Build. 77, 247-255 (2014)

3. Noh Pat, F., Xaman, J., Alvarez, G., et al.: Thermal analysis for a double glazing unit with and without a solar control film (sns-cuxs) for using in hot climates. Energy Build. 43(2-3), 704-712 (2011)

4. Freewan, A.A.Y.: Impact of external shading devices on thermal and daylighting performance of offices in hot climate regions. Sol. Energy 102, 14-30 (2014)

5. Gloria Gomes, M., Santos, A.J., Moret Rodrigues, A.: Solar and visible optical properties of glazing systems with Venetian blinds: numerical, experimental and blind control study. Build. Environ. 71, 47-59 (2014)

6. Kim, J.T., Todorovic, M.S.: Tuning control of buildings glazing. Energy Build. 63, 108-118 (2013)

7. Ye, H., Meng, X., Long, L., et al.: The route to a perfect window. Renew. Energy 55, 448-455 (2013)

8. Kostro, A, Geiger, M, Jolissaint, $\mathrm{N}$, et al.: Embedded microstructures for daylighting and seasonal thermal control. Proceedings of SPIE-the international society for optical engineering, p. 8485 (2012)

9. Garrido, P: Façade FB720, three proposals for reducing the environmental impact due to the use and construction of light façades, Proceedings of the VI International Congress on Architectural Envelopes (ICAE 2012). Tecnalia Research \& Innovation. Donostia (2012)

10. Gläser, H.J.: Large area glass coating. Von Ardenne, Dresden (2000)

11. Thelen, A.:Design of optical interference coatings. McGraw-Hill (1989) 